\title{
Comunicação como ferramenta essencial para assistência à saúde dos surdos
}

I 1 Yanik Carla Araújo de Oliveira, 2 Suely Deysny de Matos Celino,

${ }^{3}$ Gabriela Maria Cavalcanti Costa I

Resumo: Estudo de abordagem qualitativa realizado com o objetivo de revelar como os surdos percebem a comunicação com os profissionais de saúde, e compreender o significado da presença de um acompanhante oralizado como interlocutor, durante atendimento na rede pública de serviços de saúde. Foram realizadas 11 entrevistas com pessoas surdas que se comunicassem por meio da língua de sinais. As falas dos entrevistados foram traduzidas para o português, transcritas e submetidas à análise de conteúdo temática, que resultou em três categorias temáticas: as ferramentas de comunicação na assistência à saúde dos surdos; a presença do acompanhante como interlocutor; e a comunicação em Língua Brasileira de Sinais. As estratégias de comunicação com os usuários surdos adotadas pelos profissionais de saúde se mostraram ineficientes e mesmo a presença do acompanhante como interlocutor não foi suficiente para garantir uma assistência de qualidade, visto que os surdos se mostraram sujeitos passivos no seu próprio processo saúde-doença. Nesse sentido, os participantes salientaram que preferiam ser atendidos por profissionais que conhecessem a língua de sinais, no sentido de estabelecer uma comunicação direta, mantendo sua privacidade e independência.

> Palavras-chave: comunicação; assistência à saúde; surdez.

\author{
${ }^{1}$ Mestre em Saúde Pública. \\ Universidade Estadual da \\ Paraíba. Campina Grande-PB, \\ Brasil. Endereço eletrônico: \\ yanikaraujo@yahoo.com.br \\ 2 Faculdade de Ciências Médicas. \\ Campina Grande-PB, Brasil. \\ Endereço eletrônico: deysny@ \\ hotmail.com \\ ${ }^{3}$ Docente na Universidade \\ Estadual da Paraíba. Campina \\ Grande-PB,Brasil. Endereço \\ eletrônico: gabymcc@bol.com.br
}

Recebido em: 18/03/2014 Aprovado em: 18/12/2014 


\section{Introdução}

O processo de comunicação sempre foi compreendido como uma das bases estruturadoras da sociedade, desde o campo da esfera privada, nas microrrelaçōes, até a esfera pública, no convívio social, cultural, político e econômico. Está intimamente relacionado com a luta pela sobrevivência da humanidade, através da busca de conhecimentos para expandir-se e dominar o mundo (GOMES, 2007).

Pode-se considerar a comunicação como uma ferramenta imprescindível em todos os tipos de relaçôes, que só acontece de maneira satisfatória quando a mensagem é recebida com o mesmo sentido com o qual ela foi transmitida, podendo ser feita de várias maneiras, através da linguagem verbal ou não verbal, desde que seja um processo completo e coerente (SCHELLES, 2008). No campo da saúde, constitui um processo fundamental para se prestar uma assistência de qualidade, pois envolve, além dos seus aspectos intrínsecos, a escuta de forma acolhedora, não apenas com o objetivo de repassar informações para um entendimento conceitual, mas atingindo a subjetividade dos indivíduos (OLIVEIRA et al., 2008).

Em se tratando de uma pessoa surda, muitas vezes existem barreiras na comunicação que podem comprometer a interação por ocasião do encontro entre usuário e profissional, já que a falta de comunicação oral torna o surdo desintegrado da sociedade ouvinte. Ele tem dificuldade para usufruir serviços básicos, como, por exemplo, acesso a hospitais, já que os ouvintes também têm dificuldades em entender a língua dos sinais (CHAVEIRO; BARBOSA; PORTO, 2008; SOUZA; PORROZZI, 2009).

Em uma sociedade na qual a língua oral é predominante e, portanto, as pessoas necessitam se adaptar a ela para se integrarem no meio social, a população não está preparada para acolher o indivíduo surdo (DIZEU; CAPORALI, 2005). Nesse sentido, o encontro entre uma pessoa surda e o profissional de saúde parece ser permeado por dificuldades na comunicação (COSTA et al., 2009). $\mathrm{Na}$ maioria das vezes, essa comunicação se dá por meio da linguagem verbal, ou mesmo pela escrita e pelo uso de gestos, e não pela Língua Brasileira de Sinais (Libras), oficial da população surda no Brasil. Essas ferramentas não permitem uma escuta qualificada das necessidades de saúde desse usuário, nem mesmo um entendimento adequado dos cuidados de saúde ofertados pelo serviço, o que 
provoca angústia e ansiedade tanto nos profissionais quanto na pessoa surda (TEDESCO; JUNGES, 2013).

Acredita-se que, em alguns casos, a presença do intérprete seria a solução viável para os problemas de comunicação entre profissional e usuário surdo; verifica-se, entretanto, que sua atuação não contribui totalmente para a inclusão do surdo. Primeiro porque sua disponibilidade torna-se condição sine qua non para o atendimento ao usuário e, além disso, sua presença pode dificultar a relação profissional de saúde-paciente (CHAVEIRO; BARBOSA, 2005).

Diante do exposto, esta pesquisa teve por objetivo revelar como os surdos percebem a comunicação com os profissionais de saúde, e compreender o significado da presença de um acompanhante oralizado como interlocutor, durante atendimento na rede pública de serviços de saúde.

\section{Métodos}

Estudo de abordagem qualitativa realizado na Fundação Centro de Atendimento à Pessoa Portadora de Deficiência (FUNAD), localizada em João Pessoa-PB. O cenário foi escolhido apenas para localizar os sujeitos, visto que se trata de uma instituição de referência para o acolhimento desse grupo populacional.

A amostra investigada foi constituída de 11 usuários surdos acima de 18 anos de idade, que se comunicam por meio da língua de sinais, com condição cognitiva que permite a integração com a pesquisadora, e que aceitaram participar da pesquisa assinando o Termo de Consentimento Livre e Esclarecido (TCLE). Além disso, também foi utilizado o critério de saturação do conteúdo das falas.

A coleta de dados foi realizada na própria instituição em um ambiente privado, por pesquisador bilíngue, por meio do contato direto com os sujeitos surdos, sem a necessidade de um intérprete, para que fossem mantidas a privacidade e a confidencialidade das informações. As entrevistas foram gravadas em arquivo MP4, devido ao conteúdo de comunicação visual.

Foram investigadas as características sociodemográficas dos sujeitos, bem como suas experiências de comunicação na assistência prestada pelos serviços públicos de saúde, através das seguintes perguntas norteadoras: "Como você percebe a comunicação com os profissionais de saúde durante atendimento na rede pública de serviços de saúde?" e "Para você, qual o significado da presença do intérprete como mediador, entre usuários e profissionais, durante esse atendimento?”. 
As falas dos entrevistados foram traduzidas para o português e transcritas. Em seguida, os vídeos e as transcrições foram entregues a um juiz surdo bilíngue para comprovação das traduções. Esse processo foi realizado ao final de cada dia de entrevistas, durante o período de coleta dos dados. O conteúdo das entrevistas foi submetido à análise de conteúdo temática, proposta por Bardin (2011), que resultou em três categorias temáticas: "as ferramentas de comunicação na assistência à saúde dos surdos"; "a presença do acompanhante como interlocutor"; e "a comunicação em Libras".

Salienta-se o cumprimento das exigências do Conselho Nacional de Saúde mediante a Resolução no 466/2012 e, nesse sentido, a pesquisa foi devidamente autorizada pelo Comitê de Ética em Pesquisas da Universidade Estadual da Paraíba (CEP/UEPB), por meio da CAAE no 0448.0.133.000-11. Além disso, para resguardar a identidade dos sujeitos, foi registrado um código no qual cada planta do bioma nativo brasileiro corresponde a um participante, de conhecimento apenas da pesquisadora.

\section{Resultados}

Dos 11 sujeitos entrevistados, sete eram homens e quatro mulheres, com idade média de 30,6 anos, variando de 23 a 44 anos. Todos eles relataram morar com pelo menos duas pessoas no mesmo domicílio. No que se refere à escolaridade, seis tinham ensino médio; quatro, superior completo ou incompleto; e um, fundamental incompleto.

Quanto ao diagnóstico de surdez, cinco foram feitos ao nascer, três entre um e dois anos; dois entre cinco e seis anos; e um apenas aos 15 anos de idade. Do total, quatro possuíam alguém na família com o mesmo problema (irmão, primo ou sobrinho).

Em se tratando do domínio de Libras, apenas cinco aprenderam na infância (entre 02 e 08 anos), sendo que três antes dos três anos e dois dois usavam leitura labial até os oito anos. Os demais (06) aprenderam na adolescência (entre 12-19 anos), e usavam, até então, sinais domésticos e mímicas para se comunicarem. Entretanto, não obtiveram sucesso no alcance do entendimento pleno da comunicação e, com o fracasso do método oralista, aceitaram aprender a Libras e hoje é a forma predominante e mais eficiente de estabelecer sua comunicação, exaltando a necessidade dos surdos se comunicarem em língua de sinais e participarem ativamente das decisões sobre sua vida. 
No que se refere à comunicação no seu ambiente familiar, quatro relataram que ninguém de sua família de origem sabia se comunicar em Libras, e como destes, três eram casados, todos(as) o(as) companheiro(as) sabiam Libras. Os outros sete sujeitos relataram que suas mães, irmã(o)s, tia e sobrinha conheciam a Libras, sendo que em dois casos houve influência na escolha da profissão como intérprete de Libras para esses familiares.

\section{Categorias temáticas}

\section{As ferramentas de comunicação na assistência à saúde dos surdos}

É por meio da comunicação que os profissionais de saúde compreendem o usuário como ser holístico e percebem sua visão de mundo; a partir daí, são capazes de entender suas necessidades e, assim, prestar assistência adequada, minimizando seu desconforto (BRITTO; SAMPERIZ, 2010). Na área de saúde, habilidades de comunicação interpessoal são imprescindíveis na assistência a qualquer usuário, e as ações dos profissionais são pautadas pela comunicação, como ferramenta-base de trabalho, independentemente da sua formação acadêmica (CHAVEIRO et al., 2010). Os profissionais de saúde devem educar-se sobre maneiras de reduzir as barreiras e garantir a assistência à saúde para todas as pessoas (SCHEIER, 2009).

Usuários que necessitam de atenção especial, por se comunicarem de forma diferente das outras pessoas, devem estabelecer uma ligação entre o profissional e o paciente, o que exige competência e capacidade do profissional para se comunicar com o usuário da forma correta, ou seja, na língua de libras (FREITAS; SEIDL, 2011). Como a maioria dos profissionais não tem domínio desse meio de comunicação, passam a utilizar de outras ferramentas, como a linguagem escrita ou a leitura labial.

O médico escreve tudo no papel e me mostra, fica difícil explicar as coisas, sou surdo, entendo língua de sinais, o português me confunde. Tem muitas palavras em português que eu não conheço. Não dá certo. É muito difícil! (URUCUM)

O mesmo acontece com o médico, a gente tenta conversar, mas é difícil, só com leitura labial ou por escrito. Minha opinião é de que a assistência do SUS é péssima. (MONJOLEIRO)

Um estudo que realizou entrevistas com profissionais de enfermagem assinalou mais de uma possibilidade de estratégia de comunicação utilizada no atendimento a usuários surdos. Todos responderam usar a mímica durante os 
atendimentos; 94\% relataram a leitura labial; 65\%, o auxílio do acompanhante, e $42 \%$, a escrita; e apenas $1 \%$ se comunicou por meio de Libras como estratégia de comunicação. Embora algumas estratégias tenham sido apontadas pelos profissionais, os usuários surdos demonstraram ressalvas importantes quanto à eficiência delas (BRITTO; SAMPERIZ, 2010).

Essa dificuldade, vivenciada ao longo dos anos, está relacionada, entre outros aspectos, ao modo como a sociedade enxerga os sujeitos surdos. Para Strobel (2008), a maioria das pessoas, em especial os próprios profissionais de saúde, ignora as caracterísitcas e necessidades dos surdos, muitas vezes até estereotiapando-os como "deficientes"; sendo assim, os surdos precisam se adaptar a determinadas condiçôes que não lhes convêm, desrespeitando sua cultura, com suas subjetividades e identidades próprias.

A leitura labial, relatada por Monjoleiro, é muitas vezes superestimada e pode gerar problemas específicos no relacionamento com usuários surdos (BRITTO; SAMPERIZ, 2010). Muitos médicos não percebem quão poucas palavras podem ser entendidas pela leitura labial (30\%) e que a falta de comunicação eficaz pode levar a erros, contribuindo negativamente para esses usuários evitarem idas aos serviços de saúde (HOANG et al., 2011). Esse tipo de comunicação necessita de muita concentração e deixa a pessoa surda mentalmente esgotada. Além disso, bigode, sotaque, máscaras cirúrgicas tornam a leitura labial impossível (SCHEIER, 2009).

Observa-se ainda, a partir das falas, que nem mesmo a escrita constitui uma boa estratégia de comunicação para esse grupo populacional, visto que esses sujeitos também apresentam dificuldade com a língua portuguesa, apesar de apresentarem bom nível de escolaridade, já que estudos demonstraram que pessoas surdas com a pós-graduação apresentam entendimento de leitura a um nível de quarta série (SCHEIER, 2009). Dessa forma, a escrita não é o caminho ideal para a eficácia do atendimento, visto que poderia gerar constrangimentos e frustrações ao usuário surdo (BRITTO; SAMPERIZ, 2010).

Além disso, os sujeitos do estudo também relataram dificuldades devido ao vocabulário técnico dos profissionais, conforme a fala:

O médico disse que eu podia ir sozinha e escreveria tudo, mas eu não sei português profundamente, só eu sei coisas simples, além disso, ele como profissional usa palavras técnicas da saúde sobre o corpo que eu não conheço. (MARICÁ) 
As técnicas de comunicação utilizadas pelos profissionais de saúde em suas relaçóes com os pacientes determinam sobremaneira o alcance dos objetivos de qualquer ato clínico. Dessa forma, a linguagem utilizada deve se adequar às diferentes culturas dos sujeitos assistidos (SUCUPIRA, 2007). Os profissionais de saúde não devem presumir que os usuários compreendam os termos médicos (SCHEIER, 2009). Para um atendimento médico de qualidade, a comunicação com os pacientes devem levar em consideração as crenças, os valores pessoais e o contexto sociocultural de cada um (CARVALHO, 2011).

Os profissionais de saúde e a própria sociedade não dispõem de condições para um convívio harmonioso com o indivíduo surdo; sendo assim, Dizeu e Capolari (2005) entendem que grande parte da limitação dessa população não está em seus aspectos cognitivos, e sim nas possibilidades a ela oferecidas, que ignoram sua diversidade cultural e linguística, excluindo-a de processo de integração social. Muitas vezes, o surdo seja é silenciado pelo ouvinte, por não ser compreendido e, inclusive pelos profissionais de saúde.

\section{A presença do acompanhante como interlocutor}

Considerando a dificuldade na comunicação entre os profissionais de saúde e os usuários surdos, a presença de acompanhante que saiba se comunicar com essas pessoas durante os atendimentos torna-se uma prática corriqueira para a assistência à saúde dos surdos.

No médico ainda não tem interprete próprio, então vou com uma companhia ouvinte
para ela conversar com o médico, eu fico só olhando eles conversarem. (MARICÁ)
Vou com minha irmã junto ao médico do SUS... Ela interpreta e me explica as coi-
sas... Quando vou com a minha irmã é bom. (CAVIÚNA)

Conforme as falas acima, os entrevistados demonstram-se favoráveis à presença do acompanhante, já que garante a comunicação e o entendimento de ambos os lados, usuário e profissional, embora ressalte também a necessidade da presença do intérprete de língua de sinais, conforme a fala do sujeito Maricá.

A presença do intérprete de línguas de sinais em serviços públicos de assistência à saúde é garantido legalmente em nosso país pela Lei n ${ }^{\circ}$ 10.436, de 24 de abril de 2002. Segundo seu Art. 30, "as instituições públicas e empresas concessionárias de serviços públicos de assistência à saúde devem garantir atendimento e tratamento 
adequado aos portadores de deficiência auditiva, de acordo com as normas legais em vigor" (BRASIL, 2002).

Normalmente, os familiares de pessoas surdas intermedeiam as relaçōes destes com as outras pessoas, e mesmo que dominem a língua de sinais, não necessariamente atuam como intérpretes, visto que estes necessitam ser qualificados para serem mediadores entre as pessoas, de forma a interferir o mínimo possível no processo comunicativo (QUADROS, 2004). Embora os membros da família possam voluntariar-se para interpretar, isso pode impedir que os sujeitos falem francamente com os profissionais de saúde e viola o princípio da confidencialidade. Além disso, familiares podem acidental ou intencionalmente mudar o significado do conteúdo da comunicação, por não estarem familiarizados com a terminologia médica, ou podem não ser fluentes em língua de sinais (SCHEIER, 2009).

Apesar de a presença do intérprete, e na ausência deste, de um familiar, para mediar a comunicação dos surdos com o profissional de saúde, ser importante para garantir a assistência, a perda da privacidade do usuário é fator que deve ser levado em consideração, sobretudo quando se trata de um familiar, como retrata a fala:

Às vezes não é bom a mãe acompanhar, o médico disse que eu podia ir sozinha. (MARICÁ)

Essa preocupação também é confirmada pelos dados da literatura que discute a presença de uma terceira pessoa nos encontros entre usuários que usam a língua de sinais e profissionais de saúde que a desconhecem. Se por um lado pode facilitar a comunicação, também pode levar à falta de privacidade, e até mesmo de autonomia por parte dos usuários (COSTA et al., 2010). O usuário, muitas vezes, por vergonha ou constrangimento, pode até omitir informações importantes sobre o seu processo saúde-doença (OLIVEIRA; LOPES; PINTO, 2009).

Outro problema encontrado quando da presença do acompanhante no atendimento ao surdo diz respeito à passividade do usuário no encontro clínico, percebido pelos relatos:

Eu marco uma consulta e ele me faz um monte de perguntas sobre minha saúde... às vezes conversa com minha esposa e eu fico parado só olhando eles conversarem. (CAPIXINGUI)

Como eu vou com a minha mãe, ela interage com as pessoas de lá e depois interpreta tudo para mim, me explica e eu vou aprendendo. (MUTAMBO) 
Compreende-se, dessa forma, que não existe interação efetiva entre usuário

surdo e profissional de saúde; esse fator compromete sobremaneira o vínculo e, portanto, a assistência prestada, o que pode interferir no diagnóstico e até mesmo no tratamento (CHAVEIRO; PORTO; BARBOSA, 2009).

$\mathrm{O}$ encontro entre paciente e profissional de saúde precisa ser vivenciado como um espaço de troca, diálogo e aprendizado de ambas as partes (COSTA et al., 2009). No caso do paciente surdo, é o acompanhante ou intérprete quem explica o problema do usuário e recebe as orientações, o que diminui suas oportunidades de expor dúvidas e questionamentos, limitando sua individualidade e autonomia (SANTOS; SHIRATORI, 2004).

Em se tratando de individualidade considera-se, ainda, que o surdo apresenta um modo diferente de compreender o mundo, até porque, ao contrário dos ouvintes, que interagem com outras pessoas com quase todos os sentidos ao mesmo tempo, os surdos apreendem apenas pelo visual e gestual (BARBOSA, 2011), característica que deve ser considerada no processo de cuidado a esses usuários.

\section{A comunicação em Libras}

A Língua Brasileira de Sinais (Libras) foi reconhecida oficialmente no país como meio legal de comunicação e expressão das pessoas surdas a partir de 2002, através da Lei no 10.436 (BRASIL, 2002). Trata-se de uma língua natural usada pela comunidade surda, visual-espacial, articulada através das mãos, corpo e expressões faciais (QUADROS, 2004).

A aprovação dessa lei foi um avanço para a comunidade surda, acarretando mais oportunidades para os surdos, especialmente no que diz respeito ao reconhecimento de sua cultura, de sua identidade, trazendo mudanças inclusive no seu processo educacional, além da regulamentação de profissionais intérpretes (BARBOSA, 2011). Apesar disso, ainda é pouco conhecida e compreendida pela população no geral (QUADROS, 2004).

Em se tratando dos serviços de saúde, a maioria dos profissionais também não conhece a língua de sinais e não há intérpretes suficientes disponíveis (SANTOS; SHIRATORI, 2004). Isso acaba comprometendo a assistência a saúde do surdo que busca o atendimento ou até mesmo reprimindo sua procura, como explicitado nas falas a seguir: 
Se o médico soubesse língua de sinais eu me comunicaria bem com ele, mas ele não entende o que eu digo... Impossível! Eles usam muitas palavras difíceis sobre o corpo humano, doenças e outras coisas. (BUGREIRO).

O bom seria se o médico soubesse língua de sinais, para o surdo e ele poderem conversar diretamente, em língua de sinais, porque é assim que o surdo fala. Por isso poucos surdos vão ao médico. É difícil! Existem muito mais ouvintes. (MUTAMBO)

$\mathrm{Na}$ sociedade atual, as diferenças são muitas vezes desconsideradas e, dessa forma, sendo a língua oral imperativa entre as pessoas no geral, é tendencioso comportar-se como se todos os indivíduos, independentemente de suas possibilidades ou limitaçóes, fossem obrigados a adaptar-se a esse meio de comunicação. Dessa forma, a língua de sinais é comumente considerada uma linguagem inferior, sendo interpretada pelos profissionais apenas como gestos simbólicos (DIZEU; CAPOLARI, 2005).

A linguagem é considerada como instrumento de poder; assim, não se pode negar às pessoas o direito de usufruir dos benefícios de uma língua. A sociedade deve compreender a diversidade humana, aceitando a diferença linguística do surdo (CHAVEIRO; BARBOSA, 2005). Os profissionais de saúde precisam reconhecer a língua de sinais como forma de os surdos interagirem com o mundo, e cabe a eles não apenas dominar patologias, mas reduzir a barreira que os separa pela falta de comunicação adequada (CHAVEIRO; BARBOSA, 2008).

Nesse sentido, Oliveira, Lopes e Pinto (2009) sugerem que os profissionais de saúde devam não só aprender a língua de sinais, como também serem continuamente atualizados e acompanhados quanto ao desempenho na troca de informações com o surdo através da Libras. As instituições acadêmicas devem oportunizar aos futuros profissionais o aprendizado da língua de sinais, atendendo às necessidades da pessoa surda, por meio de uma formação para os profissionais que contemple a cultura dos surdos, noções básicas de língua de sinais e como se posicionar frente ao atendimento da pessoa surda (CHAVEIRO et al., 2010).

Em estudo realizado em instituições privadas de ensino superior de enfermagem, fisioterapia e odontologia no estado da Paraíba, constatou-se que estas oferecem Libras como componente optativo na grade curricular, como forma de atender às recomendações do Ministério da Educação e Cultura, na busca de formar profissionais humanistas, críticos e com uma atuação inclusiva (OLIVEIRA et al., 2012). Apesar disso, Martins (2008) alerta para o perigo da superficialidade no ensino de Libras, no sentido de apenas cumprir as determinações legais, 
recomendando que a língua de sinais tenha a mesma importância da língua oral, sendo reconhecida em todos os espaços de circulação pública.

A língua de sinais é um fator-chave no acesso e participação plenos em todas as áreas da sociedade e da vida, sem o que o surdo estaria isolado; quando se nega ou limita seu uso, estão sendo violados seus direitos humanos (MUÑOZ-BAELL et al., 2011).

\section{Considerações finais}

Os sujeitos deste estudo apresentaram algumas estratégias de comunicação utilizadas pelos profissionais de saúde durante a assistência à sua saúde, como o uso da escrita, da leitura labial, e especialmente a presença do acompanhante familiar do surdo. Todavia, essas estratégias foram apontadas como ineficientes para uma comunicação efetiva e para promover a participação plena dos sujeitos na sociedade.

Os entrevistados identificaram que, durante o encontro clínico, a comunicação é estabelecida entre os ouvintes - ou seja, o acompanhante e o profissional de saúde -, de modo que os surdos são passivos nesse processo. Foi relatada, ainda, a perda da privacidade e do protagonismo dos sujeitos quanto ao entendimento sobre seu processo saúde-doença. Por isso, alguns deles preferem ir a serviços de saúde que disponibilizam o serviço de interpretação de Libras, obedecendo à legislação brasileira, fato que não vem sendo cumprido como deveria, já que ainda há poucos locais que disponibilizam esse serviço.

Os participantes salientaram que preferiam ser atendidos por profissionais de saúde que soubessem língua de sinais, no sentido de estabelecer uma comunicação direta, mantendo sua privacidade e independência. Para tal, a qualificação dos profissionais que estão em serviço e, antes disso, a formação em nível de graduação, ainda na faculdade, para aqueles que se encontram no processo de formação profissional, é fator condicionante. Assim, seriam minimizadas tantas dificuldades relatadas pelos sujeitos surdos que buscam os serviços públicos de saúde.

Destaca-se que, mesmo tendo sido realizado em uma instituição que atende a todo o estado paraibano, sabe-se que os habitantes de algumas cidades não conseguem lá chegar devido à distância. Por isso, este estudo apresentou a limitação de não alcançar todo o estado. Recomenda-se que sejam realizados estudos complementares que alcancem lugares distantes dos grandes centros urbanos, onde notoriamente não se consegue usufruir da gama de recursos para o atendimento da população da capital. ${ }^{1}$ 


\section{Referências}

BARBOSA, L. R. S. A Língua Brasileira de Sinais como inclusão social dos surdos no sistema educacional. Polyphonía, Goiânia, v. 22, n. 1, p. 173-187, 2011.

BARDIN, L. Análise de Conteúdo. São Paulo: Edições Setenta, 2011.

BRASIL. Lei no 10.436 de 24 de abril de 2002. Dispõe sobre a Língua Brasileira de Sinais Libras e dá outras providências. Diário Oficial [da] República Federativa do Brasil. Brasília, DF, abr. 2002.

BRITTO, F. R, SAMPERIZ, M. M. F. Dificuldades de comunicação e estratégias utilizadas pelos enfermeiros e sua equipe na assistência ao deficiente auditivo. Einstein, São Paulo, v. 8, n. 1, p.80-85, jan./mar. 2010.

CARVALHO, V. D. A ressignificação da linguagem na relação multiprofissional da saúde: relatos pessoais de mulheres com câncer de mama. 2011. 194 p. Tese (Doutorado em Comunicação Social) - Universidade Metodista de São Paulo, São Bernardo do Campo, 2011.

CHAVEIRO, N.; BARBOSA, M. A. Assistência ao surdo na área de saúde como fator de inclusão social. Revista da Escola de Enfermagem da USP, São Paulo, v. 39, n. 4, p. 417-422, 2005. CHAVEIRO, N.; BARBOSA, M. A. A surdez, o surdo e seu discurso. Revista Eletrônica de Enfermagem, Goiânia, v. 06, n. 02, p.166-171, 2004.

CHAVEIRO, N.; BARBOSA, M. A.; PORTO, C. C. Revisão de literatura sobre o atendimento ao paciente surdo pelos profissionais da saúde. Revista da Escola de Enfermagem da USP, São Paulo, v. 42, n. 3, p. 578-583, 2008.

CHAVEIRO, N.; PORTO, C. C.; BARBOSA, M. A. Relação do paciente surdo com o médico. Revista Brasileira de Otorrinolaringologia, São Paulo, v. 75, n. 1, p. 174-150, 2009.

CHAVEIRO, N.; BARBOSA, M. A.; PORTO, C. C. et al. Atendimento à pessoa surda que utiliza a língua de sinais, na perspectiva do profissional da saúde. Cogitare Enfermagem, Curitiba, v. 15, n. 4, p. 639-645, 2010.

COSTA, L.S.M. et al. O atendimento em saúde através do olhar da pessoa surda: avaliação e propostas. Revista Brasileira de Clínica Médica, Botucatu, v. 7, p. 166.170, 2010.

DIZEU, L.C.T.B.; CAPORALI, S.A. A língua de sinais constituindo o surdo como sujeito. Educação e Sociedade, Campinas, vol. 26, n. 91, p. 583-597, maio-ago. 2005.

FREITAS, A.F.; SEIDL, E.M.F. Study on heteronomy in the health care to children and adolescents with special needs. Revista Bioética, Brasília, v. 19, n. 1, p. 119-140, 2011.

GOMES, R.A.L. A comunicação como direito humano: um conceito em construção. 2007. 206 p. Dissertação (Mestrado em Comunicação) - Universidade Federal de Pernambuco, Recife, 2007.

HOANG, L. et al. Assessing deaf cultural competency of physicians and medical students. Journal of Cancer Education, v. 26, n. 1, p. 175-182, 2011. 
MARTINS, V. R. O. Análise das vantagens e desvantagens da Libras como disciplina curricular no ensino superior. Revista do CEOM, Santa Catarina, ano 21, n. 28, p. 191-206, 2008.

MUÑOZ-BAELL, I.M. et al. Comunidades sordas: ¿pacientes o ciudadanas? Gaceta Sanitaria, Barcelona, v. 25, n.1, p 72-78, 2011.

OLIVEIRA, A. et al. A comunicação no contexto do acolhimento em uma unidade de saúde da família de São Carlos, SP. Interface - Comunicação, Saúde, Educação, Botucatu, v.12, n.27, p. 749-762, 2008.

OLIVEIRA, H.R.; LOPES, K.S.; PINTO, N.M.M. Percepção da equipe de enfermagem acerca da assistência prestada ao deficiente auditivo. Revista Enfermagem Integrada, Ipatinga (MG), v. 2, n. 1, p. 165-175, 2009.

OLIVEIRA, Y.C.A. de et al. A língua brasileira de sinais na formação dos profissionais de enfermagem, fisioterapia e odontologia no estado da Paraíba, Brasil. Interface-Comunicação, Saúde, Educação, Botucatu, v. 16, n. 43, p. 995-1008, 2012.

QUADROS, R. M. de. O tradutor e intérprete de língua brasileira de sinais e lingua. Programa Nacional de Apoio à Educação de Surdos - Brasília: Ministério da Educação e Cultura, 2004.

SANTOS, E. M.; SHIRATORI, K. As necessidades de saúde no mundo do silêncio: um diálogo com os surdos. Revista Eletrônica de Enfermagem, Goiânia, v. 06, n. 01, p.68-76, 2004. SCHELLES, S. A importância da linguagem não-verbal nas relações de liderança nas organizações. Revista Esfera, Brasília, n. 1, p. 1-8, 2008.

SCHEIER, D. B. Barriers to health care for people with hearing loss: a review of the literature. Journal of the New York State Nurses Association, v. 40, n. 1, p. 4-10, 2009.

SOUZA, M. T.; PORROZZI, R. Ensino de Libras para os Profissionais de Saúde: Uma Necessidade Premente. Revista Práxis. Volta Redonda, v. 1, n. 2, p. 43-46, 2009.

STROBEL, K. L. Surdos: vestígios culturais não registrados na história. 2008. 176 p. Tese (Doutorado em Educação) Universidade Federal de Santa Catarina, Florianópolis, 2008.

SUCUPIRA, A. C. A importância do ensino da relação médico-paciente e das habilidades de comunicação na formação do profissional de saúde. Interface - Comunicação, Saúde, Educação, Botucatu, v. 11, n. 23, p. 619-635, 2007.

TEDESCO, J. R.; JUNGES, J. R. Desafios da prática do acolhimento de surdos na atenção primária. Cadernos de Saúde Pública, Rio de Janeiro, v. 29, n. 8, p. 1685-1689, 2013.

\section{Nota}

${ }^{1}$ Y.C.A. de Oliveira participou da concepção e elaboração do projeto; análise e interpretação dos dados; redação do manuscrito e aprovação final da versão a ser publicada. G.M.C. Costa participou da concepção e elaboração do projeto; revisão crítica do conteúdo intelectual e; aprovação final da versão a ser publicada do referido artigo. S.D. de M. Celino participou da análise e interpretação dos dados; redação do manuscrito e; aprovação final da versão a ser publicada do referido atigo. 


\section{Abstract}

\section{Communication as an essential tool for deaf people's health care}

This qualitative study was conducted to reveal how the deaf perceive communication with health professionals, and understand the significance of the presence of an oral companion as interlocutor for care in public health services. We performed 11 interviews with deaf people who communicate through sign language. The interviewees' statements were translated into Portuguese, transcribed and subjected to thematic content analysis, which resulted in three themes: "communication tools in health care of deaf people", "the presence of the companion as an interlocutor; communication in Brazilian Sign Language". Communication strategies for deaf users adopted by health professionals are inefficient and even the presence of a companion as interlocutor could not ensure quality care, since the deaf proved taxable in their own healthdisease process. In this sense, participants stressed that they preferred to be seen by professionals who know sign language, establishing direct communication, maintaining their privacy and independence.

> Key words: communication; health care delivery; deafness. 